\title{
Material metabolism and lifecycle GHG emissions of urban road system (URS)
}

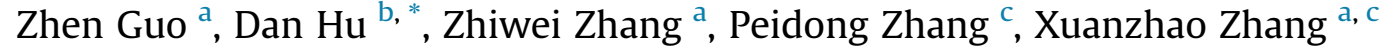 \\ ${ }^{a}$ Research Center for Islands \& Coastal Zone, First Institute of Oceanography, State Oceanic Administration, 6 Xianxialing Road, Qingdao 266061, China \\ ${ }^{\mathrm{b}}$ State Key Laboratory of Urban \& Regional Ecology, Research Center for Eco-Environmental Sciences, Chinese Academy of Sciences, 18 Shuangqing Road, \\ Beijing 100085, China \\ c Qingdao University of Science and Technology, College of Environment and Safety Engineering, 11 Fushun Road, Qingdao 266042, China
}

\section{A R T I C L E I N F O}

\section{Article history:}

Received 14 March 2017

Received in revised form

15 July 2017

Accepted 17 July 2017

Available online 19 July 2017

\section{Keywords:}

Urban road system (URS)

Material metabolism

Greenhouse gas (GHG) emission

Life cycle assessment (LCA)

Infrastructure resource management

\begin{abstract}
A B S T R A C T
The intensive activities of urban infrastructure construction lead to a considerable amount of materials flowing into cities. With these processes of material metabolism, a huge level of energy consumption occurs throughout the lifecycle. Identifying the metabolism processes enables decision makers to better understand the causes of resource and environmental issues, therefore to propose corresponding measures for optimizing urban management. Focusing on the road systems in megacities, we probed into the construction standards and conducted in-site surveying. Based on the stock model and inventory building, studies on the metabolic processes, lifecycle energy consumption, and GHG emissions were carried out. The results demonstrated that: 1) The current road system in Beijing features large stocks and small flows. In particular, the in-use stock is $164.6 \mathrm{Mt}$, mainly involving 13 types of general construction materials. Of the total stock, $79.2 \%$ is stored in roads, and the rest is stored in ancillary facilities. 2) Microcirculation roads account for relatively smaller proportions in road network rationing. Regulating the grade proportions and the spatial layouts are feasible ways to reduce the input of infrastructure resources. 3) The two main stages with massive GHG emissions are production and maintenance, in which clinker production is the largest contributing process. The key to solid waste control and emission reduction in the long term is to further improve the recycling rates and technique upgrading for new pavement materials, not simply prolonging the service years.
\end{abstract}

๑) 2017 Elsevier Ltd. All rights reserved.

\section{Introduction}

Cities are generally regarded as a complex system for sanitation, utilities, land usage, housing, and transportation; their development represents the progression of human society (Batty, 2008). However, the acceleration of global urbanization in recent decades has gradually resulted in various eco-environmental issues, such as increasing days of haze and fog, greenspace shrink, and aggravation in urban heat island effects, etc (Güneralp and Seto, 2008; Lv et al., 2015; Wei et al., 2013). Furthermore, processes with sprawl and disorder modes have brought a series of invisible resource and environmental pressures (Mathews and Tan, 2016). The urban areas only account for $2.4 \%$ of total terrestrial areas, while they consume $75 \%$ of global energy and emit nearly $80 \%$ of greenhouse gases

\footnotetext{
* Corresponding author.

E-mail address: hudan@rcees.ac.cn (D. Hu).
}

(GHGs) (Satterthwaite, 2008). From the Urban Metabolism (UM) perspective, the accelerated construction of municipal infrastructures such as buildings, roads and pipelines within the urban boundaries has led to massive inputs of external materials and energy (Kennedy et al., 2011). These huge resource pressures and environmental impacts throughout the lifecycle have currently become one of the major factors that restrict the development of cities and regions, potentially driving global changes to a larger scale (Hodson et al., 2012).

\subsection{Urban metabolism and stock study}

According to the theory of UM, the input, storage, and output of materials and energy are deemed to be the basic processes of urban ecosystems. The resource and environmental problems that occur during urbanization can be attributed to the misplacement and discoordination of these metabolic processes, either in the temporal or spatial dimension (Chen and Chen, 2012; Wang et al., 
2011). With this holistic perspective, researchers have studied the metabolism characteristics of various systems (e.g. urban system, industry system, household system) in different cities worldwide (Chen et al., 2015; Duvigneaud and Denayer-de Smet, 1977; Yang et al., 2012). Their findings provided methods and cases for exploring sustainable development paradigms. Since the concept was proposed in the 1960s and boomed after the 2000s, UM studies have become a significant focus in the field of urban ecology and industrial ecology (Kennedy et al., 2007; Zhang et al., 2015).

With the acceleration of global urbanization in recent years, studies have gradually shifted focus to the large amount of material flows that transfer from the lithosphere to the anthroposphere. Including raw and processed products, these materials flow into urban systems and accumulate rapidly in the form of durable stocks with a long lifecycle (Baccini and Brunner, 2012; Lin et al., 2017). Global human-made material stocks that mainly accumulating in the form of buildings, infrastructure, and machinery increased 23fold, reaching $792 \mathrm{Pg}( \pm 5 \%)$ in 2010 (Krausmann et al., 2017b). On one hand, the scales, composition, and changing rates of the in-use stock represent the intakes and consumption of various resources during the urban development. On the other hand, they imply the output features of the municipal solid wastes in the future (Krausmann et al., 2017a; Tanikawa et al., 1999). So far, the quantitative studies regarding urban system material stocks involve different metabolic units (e.g. metal elements, products with higher environmental risks, and municipal infrastructure), and has progressed into one of the major trends in metabolism study (Kleijn et al., 2000; Tanikawa and Hashimoto, 2009). However, due to the limited availability of data and the need for an interdisciplinary background for researchers, many difficulties and challenges have to be faced to meet the demands of current civil administration and metabolism research.

\subsection{Material metabolism and lifecycle emission of urban road system (URS)}

From the perspective of urban planning, urban road development is regarded as the basic impetus of urban space expansion. As a major type of municipal infrastructure, the crisscrossing road networks usually occupy approximately $1 / 4$ of urban built-up areas and bear the major flows of material, energy, and population (Coffin, 2007). Roads, along with residential buildings and pipelines, are collectively known as the top three largest artificial facilities in an urban system (Huang et al., 2017).

Through the stages of exploitation, production, transportation, and construction, the diverse materials that origin from the regional ecosystem are finally stored in the road systems. With the implementation of pavement upgrades and maintenance projects annually, the input flows are continuous. Consequently, the URS are rapidly developing into an infrastructure system with huge material input and energy consumption (Inyim et al., 2016). During the lifecycle of an urban system, considerable amounts of $\mathrm{CO}_{2}$ and other GHGs generated from various industrial processes are emitted (White et al., 2010). Besides, climate change may represent a risk to the road infrastructure, as changes in climate stress will affect the resources necessary for both road maintenance and construction projects (Chinowsky et al., 2013).

China's urbanization rate achieves rapid growth; moving from $10 \%$ to $50 \%$ over the span of 60 years. With this process, the urban road construction has also experienced a leap forward in terms of development (Fang, 2009). In 2014, the total length and total area of urban roads in China had reached $352,000 \mathrm{~km}$ and 6.83 billion $\mathrm{m}^{2}$ respectively, with an increase of $147.2 \%$ from 2004 (MOT, 2016). Meanwhile, as one of the top four emitters, China plays a critical role in emissions growth. China's carbon emissions reached 10 billion tons, accounting for $57 \%$ of the growth in global emissions from 2012 to 2013, and for the first time exceeded the EU's carbon emissions per capita (Friedlingstein et al., 2014). In addition to the massive consumption of materials, the global warming contributions driven by the intensive urban road construction activities in China are likewise becoming a significant issue. Identifying the metabolism processes as well as the carbon emissions throughout the entire lifecycle of URS can help researchers to evaluate the resource appropriation, potential environmental risks, and find a more sustainable route for urban infrastructure construction and management. However, most relevant studies mainly adopted social statistics, rather than to deeply investigate the "black box" of stock to precisely quantify the composition of resources (Dall'O et al., 2012). So far, no research has been reported that links the URS stock study with lifecycle inventory to further assess the GHGs emission. To fill the current gaps, in our previous study we built the stock model for calculating the stock in urban road system, and we conducted relevant analysis mainly focused on the composition and the spatial layout of the urban road stock within the study area (Guo et al., 2014). Based on our previous study, we looked further into the relationship between stock and flows, and we connected the material metabolism with Lifecycle Assessment (LCA) to discuss the how the processes of infrastructure construction impact the greenhouse gas emissions and which stage has potential spaces or possibilities for emission reduction, which may help to optimize infrastructure resources and solid waste management, and we propose sustainable policies aimed towards reaching a low-carbon city goal.

\section{Methods}

Based on the theories and methods of UM and LCA, we probed into the design standards and construction procedures of urban roads, and we built an interactive framework for analyzing the geoinformation and lifecycle material metabolism based on ArcGIS and Simapro platforms. By means of stock model calculating and inventory databases building, a quantitative study can be conducted to analyze the material metabolism, lifecycle energy consumption, and the GHG emissions of the URS (Fig. 1).

\subsection{The stock model of URS}

To precisely calculate the material stocks of URS, the road stock model proposed by Guo et al. (2014) was introduced. This model is based on a bottom-up analytical framework and covers the material stocks at multiple levels of urban roads and ancillary road works. The main equation is:

$$
\begin{aligned}
\left(M_{i}\right)_{n \times 1}= & \rho_{i} \times\left[\left(G S_{i}\right)_{n \times 1}-\left(A I_{i}\right)_{n \times 1}+\left(C U_{i}\right)_{n \times 1}+\left(F I_{i}\right)_{n \times 1}\right. \\
& \left.+\left(F C_{i}\right)_{n \times 1}+\left(G I_{i}\right)_{n \times 1}\right]
\end{aligned}
$$

where $M_{i}$ is the total stock of the $i$-th material in a road system and is acquired by multiplying its compaction density $\rho_{i}$ by its compaction volume in each stock unit; GS is the volume of all materials determined by accumulating the products of a roadway's sectional area at all levels with the corresponding length; $A I$ is the volume repeatedly calculated in at-grade intersections; $C U, F C, F I$, and $G I$ are the volumes of materials contained in curbs, curb curves, flared intersections, and ancillary facilities, respectively. The model considers two intersected roads at different levels, and classifies into 3-node and 4-node patterns. All the statistical information of road structural parameters was obtained from in-site survey and relevant construction standards, and were handled under ArcGIS platform. Compared with those studies, which were mainly derived 
The theories and frameworks of UM \& LCA
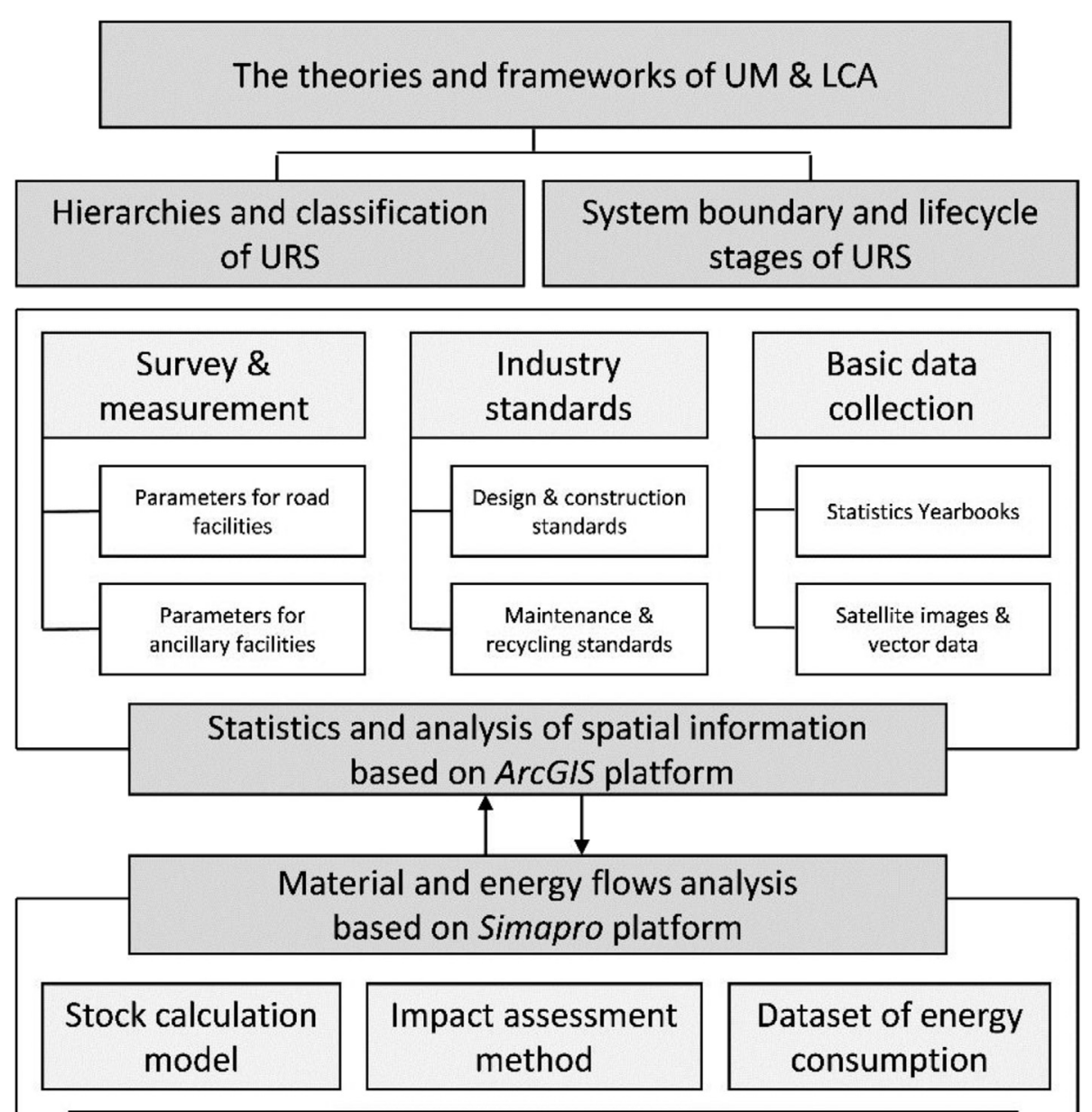

Material metabolism analysis of URS

\section{Lifecycle energy consumption analysis of URS}

\section{Greenhouse Gas emission assessment of URS}

Fig. 1. The study framework based on UM and lifecycle perspective.

from yearbook-based stock computation, this model effectively improved the data precision and ensured the structural integrity of stock systems.

\subsection{LCA and the GHGs accounting method}

As an efficient tool to assess the environmental impacts associated with all the stages of a product's life from beginning to end, LCA is widely used to study product ecological design and sustainable management (Varun et al., 2009). As the key part of LCA, Lifecycle Inventory (LCI) aims to compile the input and output data of material and energy flows during the lifecycle of a product or process (ISO, 2006b). To build a detailed inventory database, this study used the data from in-site survey, literature collection, and business database.

The procedure of Lifecycle Impact Assessment (LCIA) is mainly used to assess the potential health damage and environment impacts of the identified materials and processes from the LCI (ISO, 2006a; Klüppel, 2005). As one of the top global ecological issues, we focused on the climate changes and analyzed the GHG emissions using the Greenhouse Gas Protocol. This method, developed by the World Resources Institute (WRI) and the World Business Council for Sustainable Development (WBCSD), is a credible and effective accounting standard of greenhouse gas emissions for tackling climate change. The total GHG emissions for the inventory are calculated in the carbon dioxide equivalents $\left(\mathrm{CO}_{2} \mathrm{eq}\right)$ of all non$\mathrm{CO}_{2}$ gases $\left(\mathrm{CH}_{4}, \mathrm{~N}_{2} \mathrm{O}, \mathrm{SF}_{6}\right.$, HFCs, $\left.\mathrm{CFCs}\right)$ based on the most recent 100 year IPCC global warming potentials (GWP) (IPCC, 2007). All the foreground processes and significant background processes within the system boundary are used to calculate the carbon originating from fossil fuels and other processes (WBCSD \& WRI, 2011). Relevant analyses were conducted using Simapro. 


\section{Materials}

\subsection{Overview of the study area}

As a metropolis and the capital city, Beijing has the largest builtup area in China. Its permanent population by the end of 2015 was 21,705,000, and the vehicle quantity was 5.35 million (BSIN, 2016). The road networks in the built-up zone were mainly in a ringshaped framework. In addition to the outer boundary of the Imperial Palace as the first ring, the second to sixth rings of expressway were built successively. About 20 state-level highways expanded radially from inside out, thereby connecting the inner and outer rings. Other roads are mainly based on them, forming a network structure parallel either to longitude or latitude (BMCT, 2011). This study was targeted at the URS within 5th Ring Road. The total study area was $667.2 \mathrm{~km}^{2}$, with a total road length of $3370 \mathrm{~km}$ and a road network density up to $505 \mathrm{~km} / 100 \mathrm{~km}^{2}$, involving 382 interchanges at all levels. The URS distribution is shown in Fig. 2.

\subsection{Parameters for stock calculation}

The classification system of the URS in Beijing not only included the four levels of municipal roads (expressway, arterial road, secondary road, and branch road), but also a large number of neighborhood roads inside the blocks. To meet increasing vehicle demands, the newly constructed or reconstructed standards of neighborhood roads (also called 'streets in blocks') were upgraded to the same standard as branch roads, no longer utilized merely for pedestrian walking and bike riding. From the stock study perspective, the neighborhood roads should be considered as a part of the branch road system. Moreover, the unique road types-hutongs-mainly located in the old zone must be considered. Beijing has numerous interchanges and pedestrian overcrossings.
As ancillary road facilities, these types of stock units have span structures that required a mass of concrete and steel reinforcing bars. Thus, the urban road stock system finally involved seven stock units, including five road units and two ancillary units.

The information of road length and spatial distribution was obtained from the object-oriented extraction of QuickBird images (0.6 $\mathrm{m}$ resolution) and digitalized published thematic maps as a supplement. Information about roadway type and road width was based on a cross-sectional survey. A spatial sampling of 250 roads within the 5th Ring was selected randomly through ArcGIS. Laser range finders and GPS were used to fix positions and collect data during the in-site survey. The parameters include the width of vehicle lanes, the width of non-motor lanes, the width of central and bilateral green reserve belts, and the width of footways, etc. Except for those forbidden roads, we collected a total of 238 valid datasets covering all five type of roads. The normality test was adopted to test if the total width of each type of roads obeys normal distribution. Then the typical structures and widths at all levels were determined by statistical analysis (Fig. 3).

Node information was extracted by calculating the geometric intersection of vector data. The pseudo-nodes and redundant nodes were removed from the original data by topological analysis. The statistics of road network nodes are shown in Table 1.

The parameter settings of the pavement and subgrade structures were based on the construction standards of urban road design (MOHURD, 2008). Parameters of curb curve and flared intersection in at-grade intersections were based on the code for intersection design (MOHURD \& AQSIQ, 2011). The standard specifications of flush curb and raised curb were treated as: $0.8 \times 0.3 \times 0.1 \mathrm{~m}^{3}$, and $0.5 \times 0.1 \times 0.25 \mathrm{~m}^{3}$, respectively.

The structure complexity and sizes of both interchanges and pedestrian overcrossings are largely different. We analyzed the typical cases corresponding to the land use scale proportions of different interchanges and pedestrian overcrossings. Then the stock

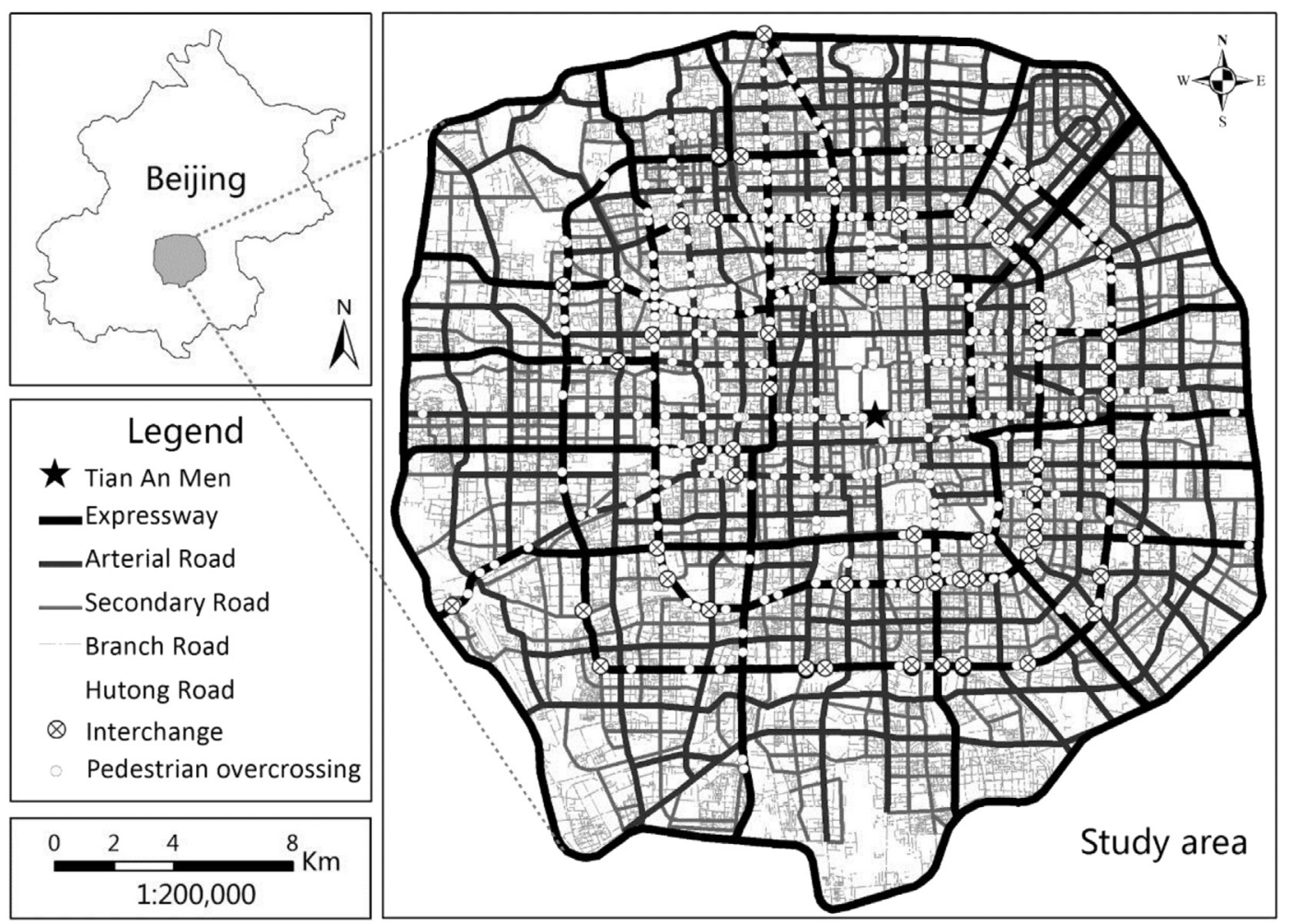

Fig. 2. Spatial distribution of the URS in the study area. 


\begin{tabular}{|c|c|c|c|c|c|}
\hline Category & Basic structure of road way & Total width (m) & Width of road way $(\mathrm{m})$ & No. of typical roads/sample size (\%) & P value * \\
\hline Hutong Roads & a & $4.73 \pm 0.99$ & $4.73 \pm 0.99 a$ & $29 / 32(90.6 \%)$ & 0.966 \\
\hline Branch Roads & $b \int$ & $12.54 \pm 3.13$ & $\begin{array}{l}7.11 \pm 1.94 a \\
2.79 \pm 1.18 b\end{array}$ & $37 / 44(84.1 \%)$ & 0.712 \\
\hline Secondary Roads & $b C$ & $23.61 \pm 4.39$ & $\begin{array}{l}15.6 \pm 4.53 a \\
4.01 \pm 1.2 b\end{array}$ & $68 / 75(90.7 \%)$ & 0.772 \\
\hline Arterial Roads & $b \sqrt{c}$ & $48.13 \pm 6.71$ & $\begin{array}{ll}13.04 \pm 3.02 \mathrm{a} & 2.60 \pm 1.27 \mathrm{~d} \\
3.97 \pm 1.00 \mathrm{~b} & 3.46 \pm 1.38 \mathrm{e} \\
5.75 \pm 1.54 \mathrm{c} & \end{array}$ & $46 / 53(86.8 \%)$ & 0.477 \\
\hline Expressways & $b c Y$ & $67.57 \pm 9.43$ & $\begin{array}{ll}16.36 \pm 2.78 \mathrm{a} & 2.91 \pm 1.12 \mathrm{~d} \\
4.53 \pm 1.05 \mathrm{~b} & 3.09 \pm 1.31 \mathrm{e} \\
11.62 \pm 2.56 \mathrm{c} & \end{array}$ & $31 / 34(91.2 \%)$ & 0.866 \\
\hline
\end{tabular}

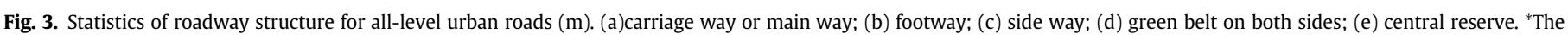
Kolmogorov-Smirnov method was adopted in test of normality. $\mathrm{P}>0.05$ means it obeys normal distribution.

Table 1

Node composition in different categories of intersections.

\begin{tabular}{|c|c|c|c|c|c|c|}
\hline & Expressways & Arterial roads & Secondary roads & Branch roads & Hutong roads & Total \\
\hline Expressways & $58(41 \%)$ & & & & & $58(41 \%)$ \\
\hline Arterial roads & $175(71 \%)$ & $149(67 \%)$ & & & & $324(69 \%)$ \\
\hline Secondary roads & $245(45 \%)$ & $471(64 \%)$ & $344(54 \%)$ & & & $1060(56 \%)$ \\
\hline Branch roads & $922(55 \%)$ & $2303(64 \%)$ & $3594(74 \%)$ & 20380 (37\%) & & $27199(45 \%)$ \\
\hline Hutong roads & $1(100 \%)$ & $66(100 \%)$ & $244(99 \%)$ & $973(66 \%)$ & $433(5 \%)$ & $1717(57 \%)$ \\
\hline Total & 1401 (55\%) & 2989 (65\%) & $4182(74 \%)$ & 21353 (38\%) & $433(5 \%)$ & 30358 (46\%) \\
\hline
\end{tabular}

Bracketed number indicates the percentage of 4-node intersections.

of supporting structure, main line, and ramps in interchanges and that of supporting structures, steel-box-girder passageways, and stairs-ramp in pedestrian overcrossings were calculated respectively. Details can be found in the supplementary files.

\subsection{Parameters for LCI building}

The inventory at each stage were built according to the predefined system boundaries. 1) At material production and preparation stages, the material stock was assumed to be the output products. For general construction material, like cement, steel, glass, and asphalt concrete, a set of China's industrial parameters were obtained from relevant industry reports and literature (Hu et al., 2014). Other parameters for resource consumption and pollutant emissions were mainly based on the relevant processes in the Ecoinvent 3.0 database; 2) At transportation stage, it is assumed that $60 \%$ of raw materials were freighted via railway and $40 \%$ by highway (NBS, 2009). The average transport distance for different materials was derived from the literature with no material loss (NBS, 2009; You et al., 2011); 3) At construction stage, relevant parameters were obtained from real project cases provided by the Beijing Municipal Committee of Transportation: premixed concrete $(25 \mathrm{kWh} / \mathrm{t})$, diesel consumption for earthwork $\left(3 \mathrm{~L} / \mathrm{m}^{3}\right)$, pavement breaking $\left(0.78 \mathrm{~L} / \mathrm{m}^{2}\right)$, ground levelling $\left(0.2 \mathrm{~L} / \mathrm{m}^{2}\right)$, and lighting $\left(26 \mathrm{kWh} / \mathrm{m}^{2}\right)$. For a certain material, the mass loss rate refers to the rate of total losses incurred during the construction stage divided by the total input. The mass loss rate for steel is $5 \%$, for asphalt is $4 \%$, and for others is $3 \%$; 4) At maintenance stage, only material for the pavement was considered. The annual maintenance rate for expressways and arterial roads is $7 \%, 10 \%$ for other roads (ZYCG, 2013); 5 ) At the recycling stage, the average pavement recycling rate of urban roads in the study area is approximately $40 \%$ (based on the survey results of the Road Administration of Beijing Municipal Commission of Transport, BMCT), and the average transport distance of construction solid waste is $20 \mathrm{~km}$. Particularly, the pavement material recycling stage mainly involves two major processes: (1) waste transportation after demolition and (2) recycling of asphalt and concrete. For concrete recycling, the processes of crushing, dismantling, separating and producing recycled aggregate are involved in the re-manufacturing stage. For asphalt, the plant mix thermal regeneration technology is mainly adopted.

\section{Results}

\subsection{Material stock analysis per unit length}

The unit-length material compositions of different road stock units were calculated by the stock model of URS (Section 2.1) and the relevant parameters for stock calculation (Section 3.2 and Supplementary file); the results are shown in Table 2 .

As shown in Table 2, the stock ratio of unit-length urban roads from 1 to 1 to $1-5$ is $18: 12: 5: 2: 1$. It is clear that under the same road length, a higher-level urban road has higher requirements for pavement and subgrade constructions and thus demands a larger per-unit material input. Among the ancillary facility units (2-1 to 2$2)$, interchanges with complex three-dimensional structures require the highest total material stock $(273 \mathrm{kt} / \mathrm{km})$ among the whole URS. Pedestrian overcrossings were mainly designed for pedestrians and non-motor vehicles, so their material input was lower than that of interchanges. The unit-length material stock of pedestrian overcrossing was approximately $22 \mathrm{kt} / \mathrm{km}$, which was only $8 \%$ of that of interchanges and was at the same level as secondary roads.

As for the type of material, the stocks of the URS are concentrated in several commonly-used building materials, such as stones, flyash, lime, sand, and cement. Steels are mainly used to build the span-typed bearing structures in interchanges and pedestrian overcrossings, and thus are only used in ancillary facilities. Other 
Table 2

Material composition of different stock units $(\mathrm{t} / \mathrm{km})$.

\begin{tabular}{|c|c|c|c|c|c|c|c|c|c|c|c|c|c|c|c|}
\hline & Stock components & Macadam & Grit & Stone chips & Mineral powder & SMA & Asphalt & Lime & Flyash & Cement & Water & Steel & PUR & APP & Total \\
\hline $1-1$ & Expressway & 58110 & 3098 & 1894 & 1082 & 8 & 731 & 2955 & 8605 & 477 & 1941 & - & - & - & 78901 \\
\hline $1-2$ & Arterial road & 38467 & 2513 & 968 & 598 & - & 432 & 1991 & 5714 & 453 & 1354 & - & - & - & 52490 \\
\hline $1-3$ & Secondary road & 15407 & 1025 & 430 & 202 & - & 147 & 854 & 2359 & 246 & 596 & - & - & - & 21266 \\
\hline $1-4$ & Branch road & 6503 & 615 & - & 85 & - & 61 & 380 & 950 & 209 & 297 & - & - & - & 9100 \\
\hline $1-5$ & Hutong & 3265 & 101 & - & 27 & - & 20 & 183 & 549 & 24 & 119 & - & - & - & 4288 \\
\hline $2-1$ & Pedestrian overcrossing & 8834 & 4069 & - & - & - & - & - & - & 3161 & 1342 & 4181 & 169 & - & 21756 \\
\hline $2-2$ & Interchange & 129575 & 60223 & - & - & 261 & 5294 & - & - & 51071 & 19735 & 7257 & - & 50 & 273466 \\
\hline
\end{tabular}

SMA (stone mastic asphalt); PUR (polyurethane plastics); APP (atactic polypropylene).

special materials, such as stone mastic asphalt (SMA), mainly served as modified asphalt in the high-level roads and interchanges. Polyurethane plastics (PUR) are mainly used in the pavement of pedestrian overcrossings. Atactic polypropylene (APP) is mainly applied as an anti-seepage material for viaducts and accounted for a low proportion among all stock units.

\subsection{The material metabolism of the URS}

According to the material compositions of unit-length stock units, total length/amount of each road unit, and relevant material metabolism parameters in LCI, a material metabolism chart of the URS within $5^{\text {th }}$-ring road was plotted to present the scales, material composition, and the flows at different lifecycle stages.

As depicted in Fig. 4, we could trace and identify the flows of each material at the five stages of material flow (input, transformation, accumulation, output, and recycle) of the system boundaries.

1) At input stage, the URS mainly involved 13 types of materials: flyash, lime, stone chips, and mineral powder were used only in roads; steels, PUR, and APP were used only in ancillary facilities; the other types were used by both stock units. The largest input was $111 \mathrm{Mt}$ found in macadam, accounting for $67.7 \%$ of total material input, while the smallest input was found in PUR, with less than $0.01 \%$ of total material input.

2) At transformation stage, the raw materials were transformed via different production and processing procedures into sizevarying asphalt concrete, grade-varying cement products, lime mortar, lime flyash-stabilized aggregate subgrade, and subgrade

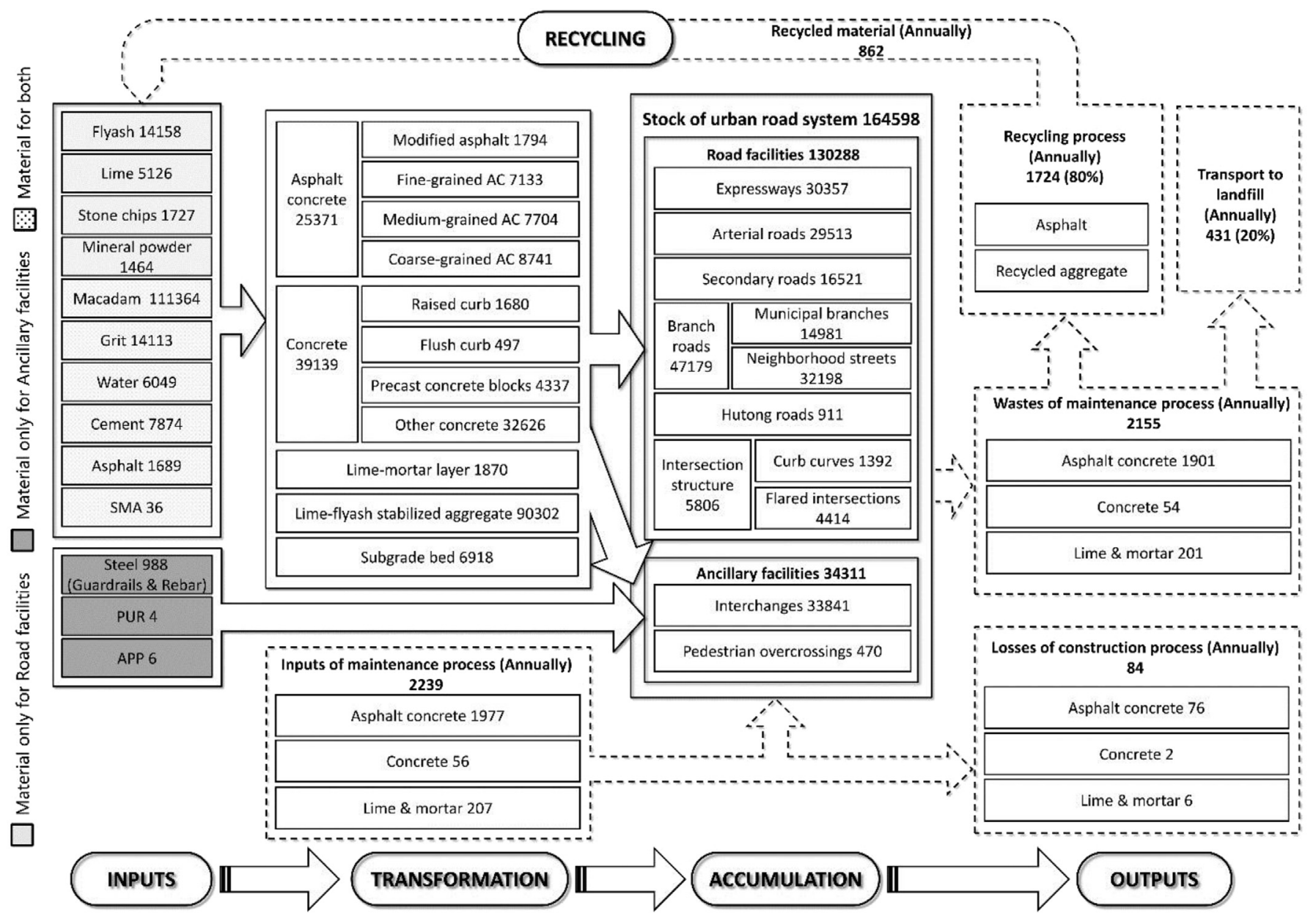

Fig. 4. The material metabolism of URS in the study area (kt). Solid arrows indicate stock processes; dashes indicate flow processes. 
bed. This stage involved the input from the first construction (163.6 Mt) and the annual material input due to pavement maintenance $(2239 \mathrm{kt} / \mathrm{a})$. Since the transformations of steels, PUR, and APP were very complex, we regarded them as the final products and directly inputted into the ancillary facility stock unit of the URS.

3) The accumulation stage was mainly manifested as the stock scales and composition of the URS. The total stock within the $5^{\text {th }}$-rings was $164.6 \mathrm{Mt}$, of which $79.2 \%$ was stored in road facilities and $20.8 \%$ in auxiliary facilities. This means that the stock of road facilities was approximately four times of that found in auxiliary facilities. The ratio of total stocks in road facilities ranking from high to low-level roads was 33:32:18:52:1. The stocks in branch roads were significantly dominant, while that in expressways and arterial roads are generally at the same level. Stocks in secondary roads and hutong roads were relatively lower. The stock due to the special structures at intersections (e.g. curb curves, flared intersections) was $5.8 \mathrm{Mt}$, accounting for about $4 \%$ of that of all road facilities. As for ancillary facilities, the material stock of interchanges (33.8 Mt) accounted for $98.6 \%$ of total stock of ancillary facilities, while that of pedestrian overcrossing is less than $2 \%$ of total auxiliary stock.

4) The output stage included the material loss due to annual road system construction and the wasted building materials due to annual pavement renewal. Specifically, the stock of annual wastes was $2155 \mathrm{kt}$, accounting for $96.2 \%$ of total outputted materials. The stock of annual material loss was $84 \mathrm{kt}$, about $3.8 \%$ of annual total outputted materials, which were mainly composed of pavement materials, such as asphalt concrete, cement, and lime mortar.

5) Among the building wastes outputted from annual pavement maintenance, approximately $80 \%$ of the waste material was recycled and half of them were involved again into road system construction; the remaining $20 \%$ was transported into the landfill.

\subsection{Energy consumption through the entire lifecycle}

As shown in Fig. 5, the lifecycle of the road system was divided into four stages: production, transportation, construction, and us. In China, the designed service life of urban roads is generally from 15 to 30 years (MOHURD, 2012). In this study, the use stage was assumed to have a 20-year service life. From the perspective of lifecycle, the use stage consisted of the repetition of two substages: maintenance and recycling. These two substages continue every year until reaching the end of service life. The maintenance substage involves the processes of material production, transportation, dismantling and construction. For the recycling substage, the processes of wastes transportation and material reusing are involved. Different stages may include the same processes.

Based on the relevant references and supplemented by survey, the above processes and LCI model were built manually in Simapro, utilizing Ecoinvent 3 as the background database (Gao et al., 2016; Tabaković, 2013; Zhang et al., 2013). Then we calculated the classweighted average energy consumption per $\mathrm{km}$ at each lifecycle stage of the URS in the study area (Fig. 5).

The total emissions during the recycling substage are calculated by the tangible GHG emission in the recycling process, minus the GHG saved by without producing the equivalent of construction material. With $1 \mathrm{~km}$ of road construction as the functional unit, the Standard Coal Equivalent (SCE) consumptions at the production, transport, and construction stages were converted to be $44.6 \mathrm{t}$, $140.1 \mathrm{t}$, and $112.7 \mathrm{t}$, respectively. The average annual SCE consumption at the use stage was $15.8 \mathrm{t}$, which included $15.7 \mathrm{t}$ at the maintenance substage and $0.1 \mathrm{t}$ at the recycle substage. Since the material production stage involved multi-level complex processes, the information regarding energy consumption could hardly be isolated. Thus, unit process accounting method was adopted at this stage. It is notable that when making a comparison of different stages based on Fig. 5, the energy consumption at productioninvolved stage, such as the production stage and the production process in maintenance substage, would be underestimated.

\subsection{Greenhouse gas emission assessment}

The GHG emissions at different stages of the URS were comprehensively evaluated by the GGP method and presented in Fig. 6. Different from unit process accounting, the GGP method presented the inventory of overall lifecycle processes at the production stage.

The GHG emission at the production stage was $1.85 \mathrm{kt} \mathrm{CO}_{2} \mathrm{eq} /$ $\mathrm{km}$, which was the largest throughout the lifecycle. The emission at the maintenance stage was $1.76 \mathrm{kt} \mathrm{CO}_{2} \mathrm{eq} / \mathrm{km}$, which was slightly smaller than that at the production stage and was the second largest among all stages. The emissions at the construction stage

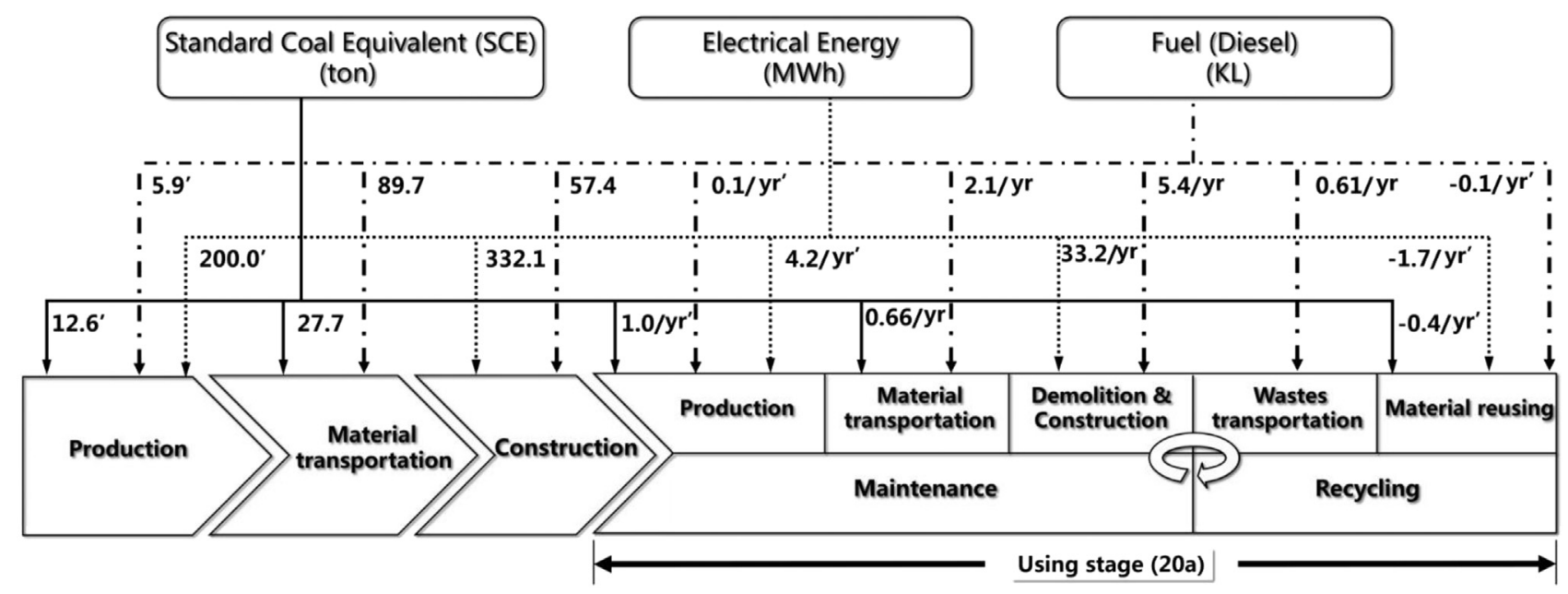

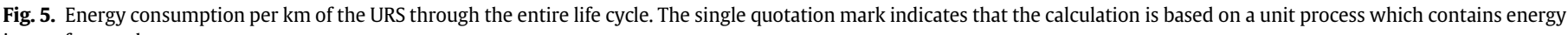
inputs from only one process step. 


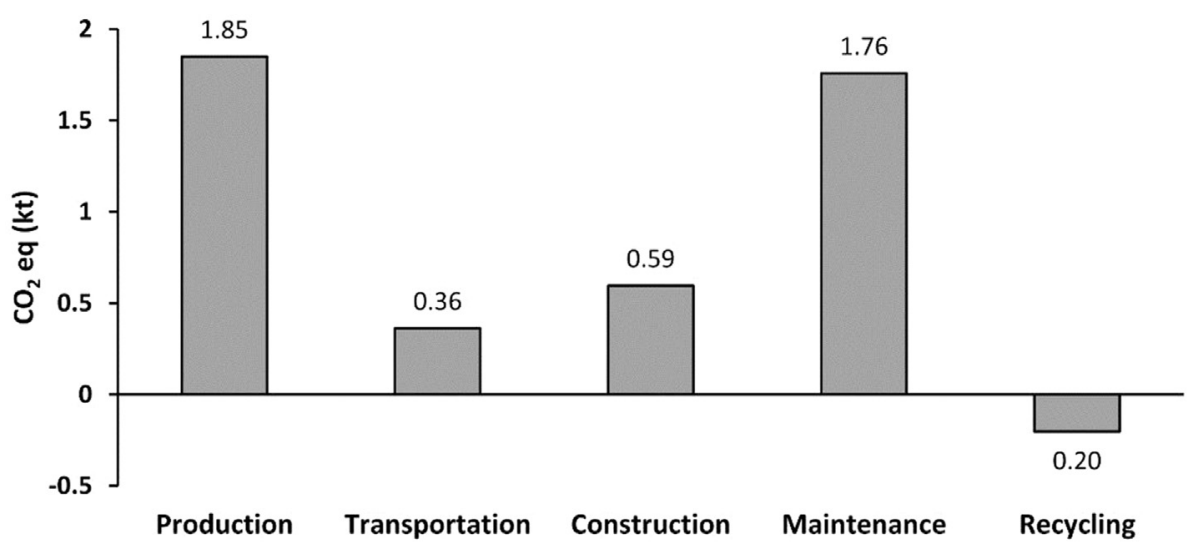

Fig. 6. The GHG emissions per km of urban road based on GGP method.

and transport stage were 0.59 and $0.36 \mathrm{kt} \mathrm{CO}_{2} \mathrm{eq} / \mathrm{km}$, respectively, which were two relatively lower stages among the entire lifecycle. The reuse of wasted building materials at the recycle stage was equivalent to storing the GHG emissions during the production of the same quantity of this material. After exclusion of waste transport, the emission was $-0.2 \mathrm{kt} \mathrm{CO}_{2} \mathrm{eq} / \mathrm{km}$.

The analysis of process contribution from the different stages was conducted to further studying the relationships between small-scaled industrial processes with GHG emissions. As listed in Table 3, the process of clinker production contributed to the emission ( $1.35 \mathrm{kt} \mathrm{CO}$ eq $/ \mathrm{km}$, or $73 \%$ of the production stage) that was the largest both in the production stage and in the entire lifecycle. The GHG emissions at the transport stage and construction stage mainly originated from the consumption of diesel and coal, and the consumption of electricity-related coal and diesel, respectively. While at the maintenance stage, the significant processes were relatively diverse.

\section{Discussion}

\subsection{Structure optimizing for URS stock}

Under the condition of guaranteeing the normal transport operating, properly adjusting the metabolism structure of the URS could not only reduce the input of excessive materials but also promote the hierarchy allocation, therefore maximizing the resource efficiency of infrastructure services.

From the perspective of road rationing (Fig. 7), an exponential distribution was observed from the length of the four-level municipal roads. The grade proportion of urban road network was $1: 1.5: 2: 4.3$. Compared with the recommendation in transport pattern studies (Chong et al., 2009; Wang et al., 2005), the built-up area of Beijing was focused on the construction of high-level roads, but apparently ignored microcirculation roads (e.g. secondary roads and branch roads), which would tend to impose excessive pressures onto the main networks. Nevertheless, the hutong roads $(212.4 \mathrm{~km})$ were mainly distributed within the second ring road, and the neighborhood roads (total length $3538.1 \mathrm{~km}$, about $68.2 \%$ of total length of all branch roads) in residential areas; enterprise and institution areas just can offset the very small proportion of microcirculation roads. We advocate to find a balance between life convenience and preservation of traditional culture. Improvements to the pavement of hutongs without serious impact to the architectural style are acceptable, so that the traffic administration could potentially open certain hutongs at rush hour. The ever-growing vehicle-flow pressure can be relieved by partially upgrading the hutong roads to branch roads (through reconstruction or expansion projects), or by turning the neighborhood roads originally sealed in blocks into major components of microcirculation roads (by opening the closed communities or building fence-free blocks).

Sensitivity analysis can be used to determine whether and to what extent the value of the output will change if there will be little change in the input conditions. In a sensitivity analysis of the stock model, up to 30 parameters were classified into 12 groups, and we adopted the direct derivation method by taking the normalized slopes of linear regression as an indicator to identify the contribution to the total stock (Fig. 8).

The parameter with the largest sensitivity was found in the thickness of road subgrade. In particular, branch roads and neighborhood roads account for $73 \%$ of the total road length in the study area, and their cross-sectional structural parameters can largely impact the scale of the entire material stocks. The quantity of road nodes represents the structural complexity of the road networks. The node number in branch roads and hutong roads are the only two parameters that negatively correlated to total stock. Given that high-level nodes usually refer to the construction of interchanges, more branch and hutong nodes mean that having more overlapping spaces under the conditions of road length is a constant,

Table 3

Top 5 processes of the different life cycle phases contributing to GHG emissions ( $\mathrm{CO}_{2} \mathrm{eq} / \mathrm{km}$ ).

\begin{tabular}{|c|c|c|c|c|c|c|c|c|}
\hline Ranks & Production & & Transportation & & Construction & & Maintenance & \\
\hline 1 & Clinker production & 1350.7 & Diesel burned in machinery & 234.3 & $\begin{array}{l}\text { Electricity production from hard } \\
\text { coal }\end{array}$ & 251.6 & $\begin{array}{l}\text { Electricity production from hard } \\
\text { coal }\end{array}$ & 498.2 \\
\hline 2 & $\begin{array}{l}\text { Electricity production from hard } \\
\text { coal }\end{array}$ & 55.0 & $\begin{array}{l}\text { Coal combustion in industrial } \\
\text { boiler }\end{array}$ & 94.8 & Diesel burned in machinery & 149.7 & Diesel burned in machinery & 371.9 \\
\hline 3 & Hard coal production & 44.9 & Diesel refining from crude oil & 28.7 & Hard coal production & 93.1 & Clinker production & 308.4 \\
\hline 4 & Diesel consuming processing & 26.1 & Anthracite coal production & 1.3 & Clinker production & 40.9 & Hard coal production & 189.7 \\
\hline 5 & Combustion of refinery gas & 20.1 & $\begin{array}{l}\text { Fuel consumption for road } \\
\text { transport }\end{array}$ & 1.1 & Diesel refining from crude oil & 18.3 & Diesel refining from crude oil & 45.5 \\
\hline
\end{tabular}




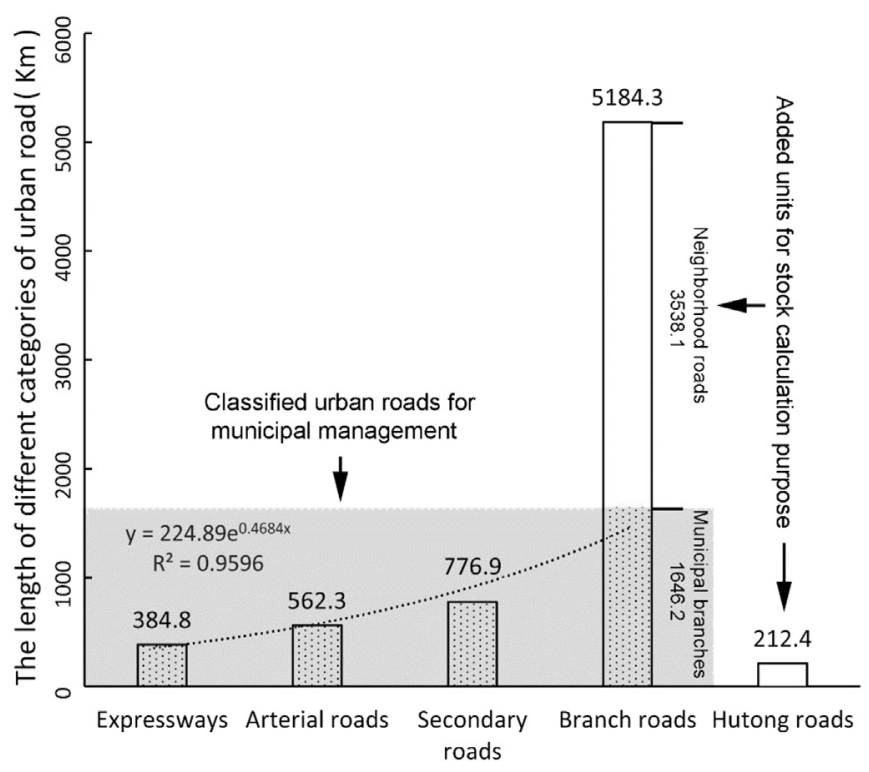

Fig. 7. The proportional allocation of different road categories in the URS.

indicating that the microcirculation structure of the URS may be crucial for regulating the existing total stocks.

\subsection{Potential solutions for GHG emission reduction}

In the analysis of lifecycle GHG emissions (Section 4.4), results show that the two major stages of GHG emissions throughout the entire lifecycle were the production and maintenance stages. The production stage features massive emissions from the clinker production process. Aside from effectively heightening the recycling rate of the subgrade materials of obsolete roads, it is advisable to promote the techniques of transforming industrial residue-such as steel slag, carbide slag, red mud, and gangue-into the alternative roadbed materials. Considering that the building materials feature substantial weight-more than 2.2 million tons annually-their transportation range should be controlled to be as short as possible in the transport stage, and the transportation distance of raw material supply could be highlighted in the course of open bidding. For the construction and maintenance stages, energy consumption both from the construction process and from the material production process contributed to GHG emissions. Scenario analysis showed that the GHG emissions from the production stage and the maintenance stage will be balanced when the service span of the current road system reaches 21 years. Thus, the contribution to GHG emission would not decline with the prolonging of service years, and attention should be diverted to the development of more durable and more environmentally-friendly road building materials. In addition, the Green Construction Concept of energy conservation, material saving, and lower environmental impacts should be advocated during these two stages. The government needs to strengthen supervision over construction activities. For builders, a series of standardized management schemes are encouraged to assign the "green goal" into daily management.

Moreover, the road network construction in the central zone of Beijing was generally finished around the 2008 Olympics, so there were no large-scale new construction projects added in the downtown area. Currently, the road system features large stocks and small flows. Based on the material metabolism results shown in Section 4.2 , the annual rate of material flow to existing material stock is $1.4 \%$ ( $2155 \mathrm{kt}$ ). However, stock and flow are interchangeable under certain conditions. Considering the increase of vehicle quantity in recent years, the lifecycle of the current road system is very likely to be shortened. The large-scale and long-lifecycle

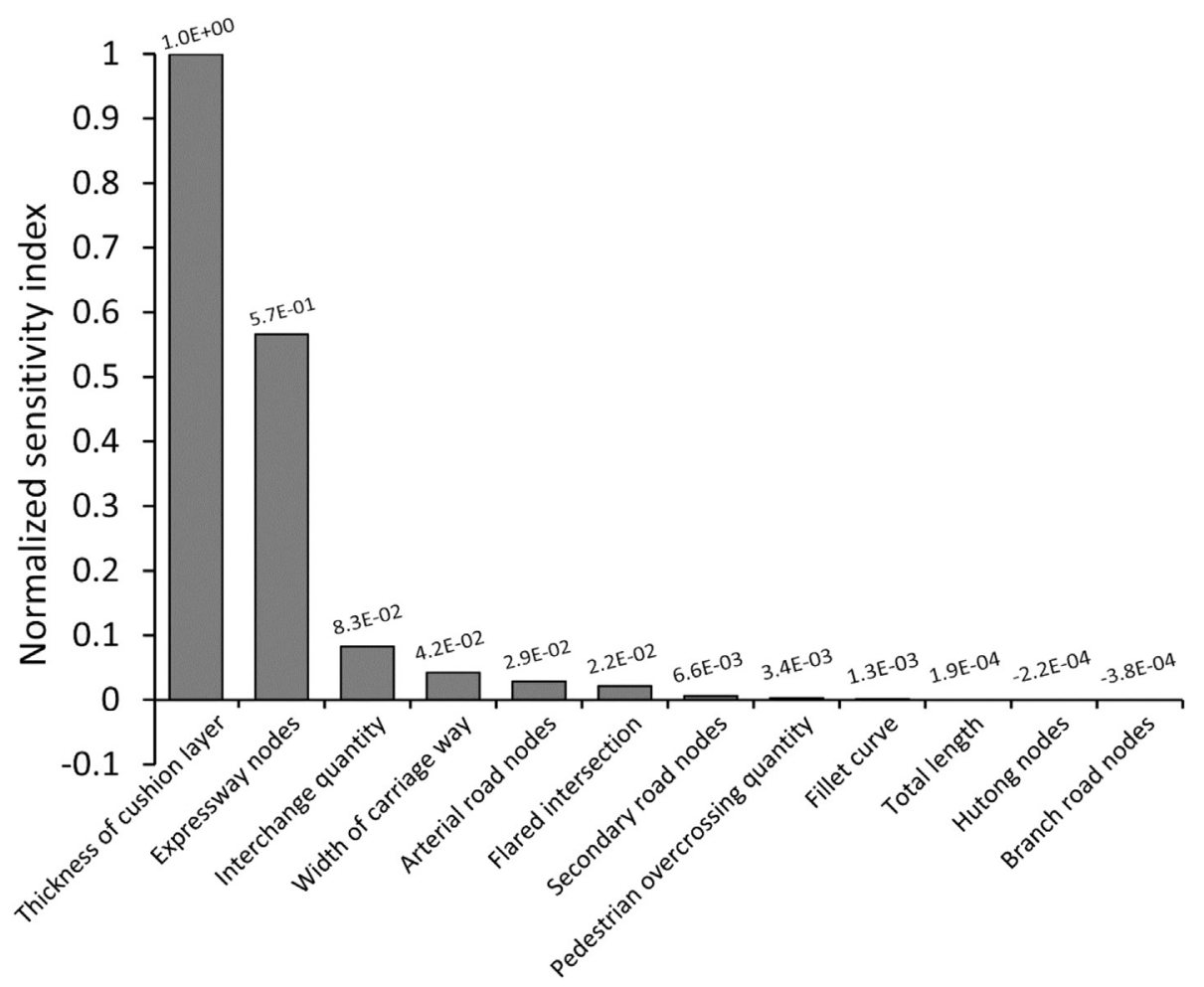

Fig. 8. Sensitivity analysis for the URS stock model. 
infrastructure stocks stored in the road systems will be accelerated to separate from the use stage. When the general system enters the times that maintenance is dominated, handling this part of solid waste would largely affect the emission levels and resource use of the road systems. The recycle stage is considered as the only carbon sink equivalent stage throughout the whole road lifecycle. Currently, the average recycle rate of urban road pavement materials in China is approximately $50 \%$, which is still very low when compared to that of Western countries (MOT, 2012). Before the extensive popularization of environment-friendly pavement materials, both technology and management should take measures to largely improve the recycle and utilization rates of road building materials. These efforts can actively cope with the abundant solidwaste output and the resulting resource and environment risks, and can help to control the GHG emissions throughout the road system lifecycle, therefore efficiently promoting the sustainability of urban infrastructure.

\section{Conclusions}

Globally, at least 25 million km of new roads are anticipated by 2050. Nine-tenths of all road construction is expected to occur in developing nations under the background of urbanization (Laurance et al., 2014). Targeting the urban road infrastructure, we built a bottom-up stock analysis system coupled with GIS and LCA database to assess the material metabolism and lifecycle GHG emissions of the URS in the megacity Beijing. This study provides methods and case for evaluating resource appropriation and exploring a sustainable mode under the large-scale, high-strength infrastructure construction during rapid urbanization. The main conclusions are as follows:

1) The current road system features large stocks and small flows. The annual rate of material flow to existing material stock is $1.4 \%$. In particular, the in-use stock is $164.6 \mathrm{Mt}$, mainly involving 13 types of general construction materials. About $79.2 \%$ of the stock is stored in roads and the remains is stored in ancillary facilities. 2) Microcirculation roads-such as branch roads, neighborhood roads, and hutong roads-account for relatively smaller proportions in road network rationing, and are potentially responsible for the traffic pressure during rush hour. Sensitivity analysis shows the node numbers of branch roads and hutong roads are negatively correlated to total stock, indicating the microcirculation structure of the URS may be crucial for regulating the existing total stocks. 3) The main stages with massive GHG emissions are production and maintenance, in which clinker production is the largest contributing process. Considering emissions from the maintenance stage may surpass those from production when the road service span reaches 21 years, the key for solid waste control and emission reduction in the long term is to further improve the recycling rates and technique upgrading for new pavement materials, not simply prolonging the service years.

Flow management is crucial for achieving the goal of lowcarbon development, whereas stock issues can be considered as the future risks or opportunities. In future studies, we plan to integrate the stock units of urban roads, buildings, and pipelines with interdisciplinary frameworks, and to investigate the relationship between stocks and flows and resource-environmental effects produced by urban metabolism, aiming to improve the planning and management of artificial environments and build resource-reduced, low-carbon, and environmentally friendly infrastructure systems.

\section{Acknowledgements}

This research was supported by the National Foundation of
Natural Sciences of China (41501595, 41571482), and the Basic Scientific Fund for National Public Research Institutes of China (2015T06). The authors would like to thank all the anonymous reviewers for their constructive comments.

\section{Appendix A. Supplementary data}

Supplementary data related to this article can be found at http:// dx.doi.org/10.1016/j.jclepro.2017.07.138.

\section{References}

Baccini, P., Brunner, P.H., 2012. Metabolism of the Anthroposphere: Analysis, Evaluation, Design. MIT Press, Cambridge.

Batty, M., 2008. The size, scale, and shape of cities. Science 319 (5864), 769-771. http://dx.doi.org/10.1126/science.1151419.

BMCT, 2011. Road administration of Beijing municipal Commission of transport (BMCT), 2011, Compilation of statistics, Bejing.

BSIN, 2016. Beijing statistical information Net (BSIN). Beijing statistics reports. http://www.bjstats.gov.cn/sjfb/bssj/jdsj/2016/ (accessed 16.12.31).

Chen, S.Q., Chen, B., 2012. Network environ perspective for urban metabolism and carbon emissions: a case study of Vienna, Austria. Environ. Sci. Technol. 46 (8), 4498-4506. http://dx.doi.org/10.1021/es204662k.

Chen, S.Q., Chen, B., Su, M.R., 2015. Nonzero-Sum relationships in mitigating urban carbon emissions: a dynamic network simulation. Environ. Sci. Technol. 49 (19), 11594-11603. http://dx.doi.org/10.1021/acs.est.5b02654.

Chinowsky, P.S., Price, J.C., Neumann, J.E., 2013. Assessment of climate change adaptation costs for the U.S. road network. Glob. Environ. Chang. 23 (4) 764-773. http://dx.doi.org/10.1016/j.gloenvcha.2013.03.004.

Chong, C., Ye, X.U., Shang, J., Huang, G., 2009. Alternatives of strategic environmental assessment for road traffic development planning-Case of Changchun City, China. Chin. Geogr. Sci. 19 (1), 25-36. http://dx.doi.org/10.1007/s11769009-0025-0.

Coffin, A.W., 2007. From roadkill to road ecology: a review of the ecological effects of roads. J. Transp. Geogr. 15 (5), 396-406. http://dx.doi.org/10.1016/ j.jtrangeo.2006.11.006.

Dall'O, G., Galante, A., Torri, M., 2012. A methodology for the energy performance classification of residential building stock on an urban scale. Energy Build. 48 (5), 211-219. http://dx.doi.org/10.1016/j.enbuild.2012.01.034.

Duvigneaud, P., Denayer-de Smet, S., 1977. L'Ecosystéme Urbs, in L'Ecosystéme Urbain Bruxellois, in Productivité en Belgique. In: Duvigneaud, P., Kestemont, P. (Eds.), Traveaux de la Section Belge du Programme Biologique International,Bruxelles, pp. 581-597.

Fang, C., 2009. The urbanization and urban development in China after the reform and opening-up (in Chinese). Econ. Geogr. 29 (1), 19-25. http://dx.doi.org/ 10.15957/j.cnki.jjdl.2009.01.005.

Friedlingstein, P., Andrew, R.M., Rogelj, J., Peters, G.P., Canadell, J.G., Knutti, R., Luderer, G., Raupach, M.R., Schaeffer, M., Vuuren, D.P.V., 2014. Persistent growth of $\mathrm{CO}_{2}$ emissions and implications for reaching climate targets. Nat. Geosci. 7 (10), 709-715. http://dx.doi.org/10.1038/ngeo2248.

Gao, L., Zhu, H.R., Cai, H.Q., 2016. Quantitatively evaluating the environmental benefits of regeneration technology in asphalt pavement (in Chinese). J. China Foreign Highw. 36 (4), 23-27. http://dx.doi.org/10.14048/j.issn.16712579.2016.04.005.

Güneralp, B., Seto, K.C., 2008. Environmental impacts of urban growth from an integrated dynamic perspective: a case study of Shenzhen, South China. Global Environ. Chang 18 (4), 720-735. http://dx.doi.org/10.1016/ j.gloenvcha.2008.07.004.

Guo, Z., Hu, D., Zhang, F., Huang, G., Xiao, Q., 2014. An integrated material metabolism model for stocks of urban road system in Beijing, China. Sci. Total. Environ. 470-471 (2), 883-894. http://dx.doi.org/10.1016/j.scitotenv.2013.10.041.

Hodson, M.A.B., Marvin, S.C., Robinson, B.D., Swilling, M.D., 2012. Reshaping urban infrastructure: material flow analysis and transitions analysis in an urban context. J. Ind. Ecol. 16 (6), 789-800. http://dx.doi.org/10.1111/j.15309290.2012.00559.x.

Hu, D., Guo, Z., Wang, Z., Xiao, Q., 2014. Metabolism analysis and eco-environmental impact assessment of two typical cement production systems in Chinese enterprises. Ecol. Inf. 26 (1), 70-77. http://dx.doi.org/10.1016/j.ecoinf.2014.05.008.

Huang, C., Han, J., Chen, W.Q., 2017. Changing patterns and determinants of infrastructures' material stocks in Chinese cities. Resour. Conserv. Recycl. 123, 43-57. http://dx.doi.org/10.1016/j.resconrec.2016.06.014.

Inyim, P., Pereyra, J., Bienvenu, M., Mostafavi, A., 2016. Environmental assessment of pavement infrastructure: a systematic review. J. Environ. Manag. 176, 128-138. http://dx.doi.org/10.1016/j.jenvman.2016.03.042.

IPCC (Intergovernmental Panel on Climate Change), 2007. IPCC Fifth Assessment Report. The Physical Science Basis. http://www.ipcc.ch/report/ar5/wg1/ (accessed 17.07.01).

ISO, 2006a. ISO 14044 Environmental Management - Life Cycle Assessment e Requirements and Guidelines. International Standard Organisation, Geneva, Switzerland.

ISO (International Organization for Standardization), 2006b. ISO 14040 
Environmental Management - Life Cycle Assessmente Principles and Framework. British Standards Institution, London.

Kennedy, C., Cuddihy, J., Engel-Yan, J., 2007. The changing metabolism of cities. J. Ind. Ecol. 11 (2), 43-59. http://dx.doi.org/10.1162/jie.2007.1107.

Kennedy, C., Pincetl, S., Bunje, P., 2011. The study of urban metabolism and its applications to urban planning and design. Environ. Pollut. 159 (8-9), 1965-1973. http://dx.doi.org/10.1016/j.envpol.2010.10.022.

Klüppel, H., 2005. The Revision of ISO Standards 14040-3-ISO 14040: environmental management life cycle assessment principles and framework - ISO 14044: environmental management life cycle assessment requirements and guidelines. J. Life Cycle Ass. 10 (3), 165. http://dx.doi.org/10.1065/ Ica2005.03.001.

Kleijn, R., Voet, E.V.D., Huele, R. 2000. Dynamic substance flow analysis: the delaying mechanism of stocks, with the case of PVC in Sweden. Ecol. Econ. 32 (2), 241-254. http://dx.doi.org/10.1016/S0921-8009(99)00090-7.

Krausmann, F., Schandl, H., Eisenmenger, N., Giljum, S., Jackon, T.D., 2017a. Materia flow accounting: global material use and sustainable development. Annu. Rev. Env. Resour. 42 (1) http://dx.doi.org/10.1146/annurev-environ-102016-060726.

Krausmann, F., Wiedenhofer, D., Lauk, C., Haasa, W., Tanikawa, H., Fishman, T. Miatto, A., Schandl, H., Haberl, H., 2017b. Global socioeconomic material stocks rise 23-fold over the 20th century and require half of annual resource use. Proc. Natl. Acad. Sci. 114 (8), 1880-1885. http://dx.doi.org/10.1073/pnas.1613773114.

Laurance, W.F., Clements, G.R., Sloan, S., O'Connell, C.S., Mueller, N.D., Goosem, M. Venter, O., Edwards, D.P., Phalan, B., Balmford, A., 2014. A global strategy for road building. Nature 513 (7517), 262. http://dx.doi.org/10.1038/nature13717.

Lin, C., Liu, G., Müller, D.B., 2017. Characterizing the role of built environment stocks in human development and emission growth. Resour. Conserv. Recycl. 123, 67-72. http://dx.doi.org/10.1016/j.resconrec.2016.07.004.

Lv, B., Zhang, B., Bai, Y., 2015. A systematic analysis of PM 2.5 in Beijing and its sources from 2000 to 2012. Atmos. Environ. 124, 98-108. http://dx.doi.org 10.1016/j.atmosenv.2015.09.031.

Mathews, J.A., Tan, H., 2016. Circular economy: lessons from China. Nature 531 (7595), 440-442. http://dx.doi.org/10.1038/531440a.

MOHURD, 2008. Ministry of Housing and Urban-rural Development of China (MOHURD), Code for Construction and Quality Acceptance of Road Works in City and Town (CJJ 1-2008). China Architecture \& Building Press, Beijing.

MOHURD, 2012. Ministry of Housing and Urban-rural Development of Chin (MOHURD), Code for Design of Urban Road Engineering (CJJ37-2012). China Architecture \& Building Press, Beijing.

MOHURD, AQSIQ, 2011. Ministry of Housing and Urban-rural Development of China MOHURD) \& General Administration of Quality Supervision, Inspection and Quarantine of China (AQSIQ), Code for Planning of Intersections on Urban Roads (GB50647-2011) (In Chinese).

MOT, 2012. Ministry of Transport of the People's Republic of China (MOT), Guiding Opinions on Speeding up the Recycling of Highway Pavement Materials. http:/ www.mot.gov.cn/sj/gonglj/gongluyh_glj/201408/t20140813_1668887.html (accessed 16.12.31)

MOT, 2016. Ministry of Transport of the People's Republic of China (MOT), Statistical Communique of Traffic and Transportation Industry Development in 2015. http://zizhan.mot.gov.cn/zfxxgk/bnssj/zhghs/201605/t20160506_2024006.html (accessed 16.12.31)

NBS, 2009. National Bureau of Statistics (NBS), China Statistical Yearbook (In
Chinese). China Statistics Press, Beijing.

Satterthwaite, D. 2008. Cities' contribution to global warming: Notes on the allocation of greenhouse gas emissions. Environ. Urban 20 (2), 539-550. http:/| dx.doi.org/10.1177/0956247808096127.

Tabaković, A., 2013. Recycled asphalt (RA) for pavements. In: Tam, V.W.Y. Labrincha, J.A., Ding, Y., Brito, J.d. (Eds.), Handbook of Recycled Concrete and Demolition Waste. Woodhead Publishing, pp. 394-423. http://dx.doi.org/ 10.1533/9780857096906.3.394.

Tanikawa, H., Hashimoto, S., 2009. Urban stock over time: spatial material stock analysis using 4d-GIS. Build. Res. Inf. 37 (5-6), 483-502. http://refhub.elsevier. com/S0048-9697(13)01185-6/rf0225.

Tanikawa, H., Matsumoto, T., Imura, H., 1999. Estimation and evaluation of the material stocks embodied in urban civil infrastructures. Environ. Syst. Res. 27, 347-354. https://www.jstage.jst.go.jp/article/proer1988/27/0/27_0_347/_pdf.

Varun, Bhat, I.K., Prakash, R., 2009. LCA of renewable energy for electricity generation systems-a review. Renew. Sust. Energy Rev. 13 (5), 1067-1073. http:// dx.doi.org/10.1016/j.rser.2008.08.004.

Wang, J.J., Wang, J.P., Peng, Z.Q., 2005. Discussion on appropriate grade proportion of urban road network (in Chinese). Urban Transp. China 3 (1), 37-42. http:// dx.doi.org/10.13813/j.cn11-5141/u.2005.01.011.

Wang, R., Li, F., Hu, D., Li, B.L., 2011. Understanding eco-complexity: social-economic-natural complex ecosystem approach. Ecol. Complex 8 (1), 15-29. http:// dx.doi.org/10.1016/j.ecocom.2010.11.001.

WBCSD, WRI, 2011. World Business Council for Sustainable Development and World Resource Institute, Product Life Cycle Accounting and Reporting Standard. http://www.ghgprotocol.org/files/ghgp/public/Product-Life-Cycle-AccountingReporting-Standard-EReader_041613.pdf (accessed 16.12.31).

Wei, Z., Wu, S., Zhou, S., Lin, C., 2013. Installation of impervious surface in urban areas affects microbial biomass, activity (potential C mineralisation), and functional diversity of the fine earth. Soil Res. 51 (51), 59-67. http://dx.doi.org/ 10.1071/SR12089.

White, P., Golden, J.S., Biligiri, K.P., Kaloush, K., 2010. Modeling climate change impacts of pavement production and construction. Resour. Conserv. Recycl 54 (11), 776-782. http://dx.doi.org/10.1016/j.resconrec.2009.12.007.

Yang, D., Gao, L., Xiao, L., Wang, R., 2012. Cross-boundary environmental effects of urban household metabolism based on an urban spatial conceptual framework: a comparative case of Xiamen. J. Clean. Prod. 27 (6), 1-10. http://dx.doi.org/ 10.1016/j.jclepro.2011.12.033.

You, F., Hu, D., Zhang, H.T., Guo, Z., Zhao, Y.H., Wang, B.N., Yuan, Y., 2011. Carbon emissions in the life cycle of urban building system in China - a case study of residential buildings. Ecol. Complex 8 (2), 201-212. http://dx.doi.org/10.1016/ j.ecocom.2011.02.003.

Zhang, W.P., Yang, T.X., Chen, Y.M., Zhao, G., Wang, S.B., 2013. Life cycle assessment of municipal solid waste treatment: a comparative literature review (in Chinese). Environ. Sci. Technol. 36 (1), 69-73. http://dx.doi.org/10.3969/ j.issn.1003-6504.2013.01.016.

Zhang, Y., Yang, Z., Yu, X., 2015. Urban metabolism: a review of current knowledge and directions for future study. Environ. Sci. Technol. 49 (19), 11247-11263. http://dx.doi.org/10.1021/acs.est.5b03060.

ZYCG, 2013. Evaluation Report on Operation Situation and Investment Prospect of Highway Maintenance Industry in China 2014-2018 (In Chinese). Zhiyan Consulting Group of China (ZYCG), Beijing. 